\title{
Effects of Protein Deprivation from the Neonatal Period on Lung Collagen and Elastin in the Rat
}

\author{
M. KALENGA AND Y. EECKHOUT \\ University Clinics, Department of Pediatrics, B.P.123, Kinshasa 11, Zaïre [M.K.]; and Laboratoire de Chimie \\ Physiologique, Institute of Cellular and Molecular Pathology, University of Louvain, Faculty of Medicine, \\ Brussels, Belgium [Y.E.]
}

\begin{abstract}
We have previously reported mechanical lung alterations in rats fed a protein-deficient diet from neonatal period to postnatal day $49(12$ and $8 \%$ protein versus a control $15 \%$ protein diet). From saline vol-pressure analysis, lungs from protein-deficient rats showed lower recoil pressure and needed higher pressure to rupture. In our study we have measured the collagen and elastin contents of homogenates of the lungs previously used for airfilling experiments. Results show that protein-deficient rats had lesser amounts of collagen and elastin per lung. Nevertheless tissue concentration of collagen remained constant, whereas elastin concentration was severely decreased. The decrease in lung recoil pressure is thought to be related to the lowered elastin concentration. Thus elastin accumulation, which mainly occurs between postnatal $\mathrm{d} 12$ and 20 , is predominantly affected by early protein deficiency with a consequent lack of increase in lung elasticity. The increased rupture pressure in protein-deficient rat lungs occurs despite the maintenance of the tissue concentration of collagen and suggests a role for other factors in this process. (Pediatr Res 26:125-127, 1989)
\end{abstract}

Morphologic, biochemical, and mechanical properties of the growing rat lung are well documented (1-5). Of interest is the correlation between connective tissue accumulation, especially collagen and elastin, and changes in mechanical behavior of the lung (4). Absolute collagen content and collagen concentration increase in a linear fashion from postnatal d 4 into adulthood in proportion to lung size. The pressure at which the saline inflated lung ruptures increases in parallel. The lung elastin concentration rises slowly from d 4 to 12 , increases 3 -fold between $\mathrm{d} 12$ and 20 , then falls to a constant level in the adult. These major changes in elastin concentration between d 12 and 20 are associated with an increase in lung elasticity measured as recoil pressure.

We have previously demonstrated differences in the pattern of deflation vol pressure curves of saline filled lungs of rats fed on a protein-restricted diet either from the neonatal period or after weaning. Lungs of rats fed on a diet restricted in protein from the neonatal period had decreased recoil pressure (6), whereas protein restriction from $\mathrm{d} 28$ resulted in a moderately increased recoil pressure (7). Inasmuch as we know from the observations of Myers et al. (8) that protein-deficiency for $3 \mathrm{wk}$ in weaned

Received January 11, 1989; accepted March 15, 1989.

Correspondence reprint requests Y. Eeckhout, Dr.Sc., Laboratoire de Chimie Physiologique, UCL 75.39, Avenue Hippocrate, 75, B-1200 Bruxelles, Belgium.

Supported by the Belgian Fonds de la Recherche Scientifique Médicale and by the Belgian State-Prime Minister's Office-Science Policy Programming (interuniversity attraction poles, Grant 7bis, and concerted actions, Grant 88/93-122).

M.K. was supported by a fellowship from the World Health Organization. Y.E. was a Research Associate of the National Fund for Scientific Research (Belgium). rats produces an increase in lung elastin concentration, our second experiment could lend support to their conclusions. We had also observed an increase in the pressure at which the lung of protein-deficient rats ruptured. This increase could also have resulted from alterations in collagen or (and) elastin content of the lung. The major mechanical properties of lungs from rats restricted in protein from neonatal period are summarized in Table 1.

The purpose of our study was to determine the amounts of collagen and elastin in lungs of rats restricted in protein from the postnatal d 8 until d 49 in our first experiment. The assays were performed on the same lung homogenates and results were analyzed in relation to lung wt, DNA and total protein content, and to mechanical findings previously described (6).

\section{MATERIALS AND METHODS}

Animals, diet compositions, mechanical procedures, and methods for tissue homogenization have been described in a previous study (6). Briefly, pathogen-free male Wistar rats were obtained on the 1st postnatal day and nursed in litters of eight. In the protein-restricted group mothers were fed diets containing 15,12 , and $8 \%$ protein during the $1 \mathrm{st}$, 2nd and $3 \mathrm{rd}$ wk of lactation, respectively, and the offspring were then maintained on the $8 \%$ protein diet until the end of the experiment. Control lactating mothers and, thereafter, control offspring received a $15 \%$ protein diet. The animals were anaesthetized and killed by exsanguination on d 49. Lung mechanics were determined by vol pressure analysis with air or saline inflation and deflation. The lungs were then inflated to the point of rupture. After completion of the mechanical tests with air, the lungs were carefully dissected from extrapulmonary airways and vessels, blotted dry, and weighed. The right lobe was homogenized in ice cold $0.3 \mathrm{M}$ sucrose $(10 \% \mathrm{w} / \mathrm{v})$ buffered at $\mathrm{pH} 7.4$ with $3 \mathrm{mM}$ imidazole-HCl. Protein and DNA contents were determined.

In our study collagen and elastin contents were estimated by hydroxyproline determination. The total hydroxyproline content of the homogenates was measured by the procedure of Kivirikko et al. (9). The method involves hydrolysis in $6 \mathrm{~N} \mathrm{HCl}$ at $110^{\circ} \mathrm{C}$ overnight, oxidation with chloramine- $\mathrm{T}$, extraction of interfering substances with toluene, heating and reaction of the resultant pyrrole to a chromophore with Ehrlich's reagent. The elastin content of another sample of the homogenate was determined according to the method of Lansing et al. (10) as modified by Jackson and Cleary (11). Essentially, samples were boiled in 0.1 $\mathrm{N} \mathrm{NaOH}$ for $50 \mathrm{~min}$ and allowed to cool; the insoluble residues were washed three times with cold $0.1 \mathrm{~N} \mathrm{NaOH}$ and three times with cold water. The final residues were hydrolyzed in $6 \mathrm{~N} \mathrm{HCl}$ and analyzed for hydroxyproline content as above. The amino acid composition of this fraction was determined with an amino acid analyzer (Liquimat III, Kontron, Switzerland); it was found 
Table 1. Summary of previously reported mechanical changes in saline filled lungs of rats fed diet containing $15 \%(P 15)$ or $8 \%$ $(P 8)$ of protein from the neonatal period (6)

\begin{tabular}{lrl}
\hline & $(\mathrm{P} 15)$ rats* & (P8) rats* \\
\hline $\mathrm{V}_{\max } \dagger(\mathrm{mL})$ & $8.6 \pm 0.3$ & $4.9 \pm 0.2 \ddagger$ \\
$\mathrm{V}_{\max }(\mathrm{mL} / \mathrm{g}$ lung) & $10.0 \pm 0.4$ & $9.2 \pm 0.3$ \\
Recoil pressure $\left(\mathrm{cm} \mathrm{H}_{2} \mathrm{O}\right)$ at $73 \%$ deflation & $4.2 \pm 0.4$ & $3.3 \pm 0.3 \S$ \\
$\mathrm{V}_{\mathrm{RP}}(\mathrm{mL})$ & $11.3 \pm 0.4$ & $6.6 \pm 0.3 \ddagger$ \\
$\mathrm{V}_{\mathrm{RP}}(\mathrm{mL} / \mathrm{g}$ lung $)$ & $13.6 \pm 0.4$ & $12.5 \pm 0.5$ \\
$\mathrm{P}_{\mathrm{RP}}\left(\mathrm{cm} \mathrm{H} \mathrm{H}_{2} \mathrm{O}\right)$ & $18.5 \pm 1.7$ & $23.6 \pm 1.3 \ddagger$ \\
\hline
\end{tabular}

* Values are means \pm SEM for $8(\mathrm{P} 15)$ rats and $10(\mathrm{P} 8)$ rats.

$+\mathrm{V}_{\max }$ was determined at $10 \mathrm{~cm} \mathrm{H}_{2} \mathrm{O}$.

$\ddagger p<0.001$ versus control rats; $\S p<0.05$.

Abbreviations: $\mathrm{V}_{\max }$, maximal lung vol; $\mathrm{V}_{\mathrm{RP}}$, vol at the point of lung rupture; $P_{R P}$, pressure at the point of lung rupture.

similar to that reported by Foster (12) for elastin and its purity was corroborated by the absence of methionine, cysteine, and histidine residues. Collagen hydroxyproline content was calculated by subtracting the elastin hydroxyproline from the total hydroxyproline of the homogenate. The factors for the conversion of hydroxyproline weight into collagen weight and into elastin weight were 7.41 (13) and 43.5 (14), respectively.

Results are presented as means \pm SEM. Statistical significance of differences between control and test groups was assessed by an unpaired $t$ test.

\section{RESULTS}

The biochemical characteristics of the lungs are summarized in Table 2. Lung wt, protein, and DNA content values have been discussed previously (6) and are shown to facilitate interpretation of the results.

Total collagen per lung was significantly lower in the proteindeficient group (55\% of control value). The collagen deficiency was paralleled by deficiencies in the lung wt and DNA content. Thus collagen content expressed both per wt and per DNA content of the lung was not different between the two groups. However, when results were expressed per total protein content, the lungs from protein-deficient rats appeared to contain $23 \%$ more collagen. We did not find any difference when collagen was related to saline maximal lung volume $(1.03 \pm 0.03$ and 1.00 $\pm 0.04 \mathrm{mg} / \mathrm{mL}$ for control and test rats, respectively). No relationship was found between the collagen tissue concentration and the increased rupture pressure in malnourished rat lungs.

Lung elastin content was altered to a greater extent than collagen. Indeed total lung elastin was dramatically decreased in protein-deficient rats ( $35 \%$ of control value) and, in contrast to the collagen content, was also lower when expressed per lung wt and DNA content. However, the elastin content was unchanged, when expressed on the basis of total protein. The amino acid composition (percent) of lung elastin of a protein-deficient rat (first values) was similar to that of a control rat (second values): glycine (40 and 38\%); alanine (21 and $21 \%$ ); proline (11 and $15 \%)$; valine (11 and $11 \%$ ); leucine ( 8 and $8 \%$ ); lysine ( 3 and $1 \%)$; tyrosine, phenylalanine, and isoleucine ( 2 and $2 \%)$; all the other amino acids were not detected (less than $1 \%$ ).

We have compared the deficit in the elastin concentration to the loss of elastic properties of the lungs of protein-restricted rats. Lung recoil was measured according to Nardell and Brody (5) from saline vol pressure curves, corrected for maximal volume, as the pressure at $73 \%$ deflation (see Table 1 ). The loss in elastic properties $(-21 \%$ of control value) thus parallels but does not equal the deficit in elastin concentration $(-34 \%)$.

\section{DISCUSSION}

The results of our study show that protein-deprivation in the rat from the neonatal period produces a reduction in lung
Table 2. Biochemical characteristics of the lungs of control (P15) and protein-deficient (P8) rats (mean \pm SEM)

\begin{tabular}{ccc} 
& $\begin{array}{c}\text { (P15) rats* } \\
(n=12)\end{array}$ & $\begin{array}{c}(\mathrm{P} 8) \text { rats } \\
(n=10)\end{array}$ \\
\hline Body wt (g) & $174 \pm 3$ & $99 \pm 2$ \\
Lung wt: wet (g) & $0.86 \pm 0.02$ & $0.53 \pm 0.01 \dagger$ \\
wet (\% body wt) & $0.50 \pm 0.01$ & $0.52 \pm 0.01$ \\
dry/wet (\%) & $21.4 \pm 0.1$ & $21.0 \pm 0.2$ \\
DNA: $\mathrm{mg} / \mathrm{lung}$ & $5.20 \pm 0.14$ & $3.14 \pm 0.10 \dagger$ \\
$\mathrm{mg} / \mathrm{g}$ lung & $6.10 \pm 0.15$ & $5.98 \pm 0.16$ \\
Protein: $\mathrm{mg} / \mathrm{lung}$ & $91.8 \pm 2.8$ & $42.9 \pm 1.2 \dagger$ \\
$\mathrm{mg} / \mathrm{g}$ lung & $107 \pm 2.8$ & $81.6 \pm 1.4 \dagger$ \\
$\mathrm{mg} / \mathrm{mg}$ DNA & $17.1 \pm 0.5$ & $13.7 \pm 0.3 \dagger$ \\
Collagen: $\mathrm{mg} / \mathrm{lung}$ & $8.89 \pm 0.32$ & $4.89 \pm 0.17 \dagger$ \\
$\mathrm{mg} / \mathrm{g}$ lung & $10.2 \pm 0.4$ & $9.41 \pm 0.40$ \\
$\mathrm{mg} / \mathrm{mg}$ DNA & $1.70 \pm 0.04$ & $1.56 \pm 0.11$ \\
$\mu \mathrm{g} / \mathrm{mg}$ protein & $96.3 \pm 4.3$ & $118 \pm 6.35 \ddagger$ \\
$\mathrm{mg} / \mathrm{g}$ lung & $6.65 \pm 0.54$ & $2.30 \pm 0.23 \dagger$ \\
$\mathrm{mg} / \mathrm{mg}$ DNA & $7.83 \pm 0.55$ & $5.21 \pm 0.55 \ddagger$ \\
$\mu \mathrm{g} / \mathrm{mg}$ protein & $1.23 \pm 0.10$ & $0.87 \pm 0.08 \ddagger$ \\
Elastin: & $69.6 \pm 5.5$ & $65.2 \pm 5.5$ \\
\hline
\end{tabular}

* Lung wt, DNA, and protein content for 15 rats.

$\dagger p<0.001$.

$\ddagger p<0.05$.

connective tissue components as measured by collagen and elastin determinations. We had previously observed that proteindeficient rats, although fed ad libitum with an isocaloric diet, reduced their food intake so that their calorie consumption was about $30 \%$ less than that of the controls; their protein intake was reduced by $65 \%(6)$. Thus the anomalies observed in the present study might result from a mixed protein-energy deficiency with a predominant protein deficit similar to the most common form of malnutrition of children in developing countries.

Inasmuch as our assay methods for collagen and elastin are based on their hydroxyproline content, one could argue that the observed alterations result from changes in the hydroxyproline content of these proteins. This cannot be totally excluded for collagen if there were dramatic changes in the proportions of the different collagen types (13), but even then one would not expect more than a few percent modification in hydroxyproline content. The hydroxyproline content of elastin is not so well documented and could be more variable, but the observed amino acid composition of lung elastin of protein-deprived rats did not differ from that of the controls (data not shown). In addition, the elastin content of the control lungs was similar to those reported by Myers et al. (8) and by Sahebjami and MacGee (15). Moreover, the elastin contents of the rat lungs were too low to be quantitated by gravimetric techniques. Determination of the specific cross-linking amino acids, desmosine, and inodesmosine, was not used either because their concentrations in lung elastin vary with age (16).

Both the collagen and elastin contents of the lung were reduced when protein restriction was started during the first $3 \mathrm{wk}$ of life in the rat, but the difference in the decrease of the two structural proteins is of some interest. Indeed total collagen content was decreased proportionally to lung wt so that its concentration remained constant, whereas elastin content was reduced to such an extent that even when expressed in term of concentration it remained lower than in controls. A similar pattern was observed when the two compounds were expressed as a function of lung cell number as estimated by the DNA content. In the same way, whereas elastin content decreased in parallel to total lung protein, the collagen fraction appeared to be relatively spared. One explanation for such a difference may be that collagen and elastin are modulated differently in the growing rat lung. In our experiment the protein restriction was started at the most important period of elastin biosynthesis which mainly occurs between $\mathrm{d} 12$ and 20 
and slows thereafter (4). Thus the effects of protein restriction during such a crucial period of elastin accumulation should be prominent. However, lung collagen, whose change is linear and directly related to lung size, should not be affected in the same way. The influence of the time at which protein deficiency is started with regard to the period of elastin accumulation in the growing rat is supported by the rise of elastin concentration in the lung when protein deficiency is started after d 21 (8). We consider from these different findings that in our study the decrease in collagen and in elastin were due to reduced biosynthesis rather than to increased breakdown. This conclusion is also suggested by the failure to decrease lung elastin concentration when young rats are submitted to a more severe food restriction (15).

The analysis of the changes in collagen and elastin in relation to lung mechanics is appropriate because collagen and elastin play essential roles in the mechanical properties of the lung (16, 17). We have previously demonstrated a decreased recoil pressure in the lungs of the protein-deficient rats used in this study. The present observations suggest that loss of lung elasticity is due to the decrease in elastin concentration. Lung tissue elasticity is well-correlated with elastin concentration in the growing rat (5) and elastin degradation by intratracheal or intraperitoneal administration of elastase results in a loss of lung elastic recoil (1820). In our experiments, the fall in lung elastic recoil does not equal the loss in lung elastin concentration $(21$ and $34 \%$ of control values for recoil pressure and elastin concentration, respectively). It is known that in the growing rat lung the pressure recoil doubles whereas elastin concentration increases 3-fold between 12 and 20 postnatal days. Thus the relationship between the two parameters, although close, is not linear.

It has also previously been demonstrated in the same test animals that, when expressed per lung wt, the maximal vol of saline inflated lung (at $10 \mathrm{~cm} \mathrm{H}_{2} \mathrm{O}$ ) and the vol at the point of rupture were unaltered in protein-deficient rats. However, the pressure at the point of rupture was higher than in controls. Maximal vol and tissue integrity of saline-filled lung are thought to be dependent on collagen content $(5,6)$. Inasmuch as collagen concentration is not affected by protein deficiency, we would not expect any difference between these parameters. The reason of the increase of lung rupture pressure despite the unchanged collagen concentration cannot be explained by the results of our study. Inasmuch as several other parameters including lung size, alveolar development, connective tissue quality, and interactions between these factors, are of importance in the mechanical properties of the lung, additional morphologic and biochemical data are needed to understand these properties.

In conclusion, it appears that protein deprivation in the rat from the neonatal period severely impairs the accumulation of lung elastin with a consequent loss in lung elasticity. The lung collagen shows quantitatively less important changes. The in- creased rupture pressure does not parallel the collagen concentration and needs further investigation.

Acknowledgments. The authors gratefully acknowledge Prof. C. Gaultier (Paris) and Dr. J. C. Henquin (Brussels) for helpful advice and suggestions, Prof. F. Van Hoof (Brussels) for the amino acid analyses, Prof. R. De Meyer (Brussels) for continuous interest and support, Dr. D. R. Davies (London) for grammatical improvement of the manuscript, and Mr. Y. Marchand for outstanding secretarial assistance.

\section{REFERENCES}

1. Burri PH 1974 The postnatal growth of the rat lung. III. Morphology. Anat Rec 180:77-98

2. Burri PH, Dbaly J, Weibel ER 1974 The postnatal growth of the rat lung. I. Morphometry. Anat Rec 178:711-730

3. Brody JS, Vaccaro C 1979 Postnatal formation of alveoli: interstitial events and physiologic consequences. Fed Proc 38:215-223

4. Powell JT, Whitney PL 1980 Postnatal development of rat lung. Changes in lung lectin, elastin, acetylcholinesterase and other enzymes. Biochem $\mathbf{J}$ 188:1-8

5. Nardell EA, Brody JS 1982 Determinants of mechanical properties of rat lung during postnatal development. J Appl Physiol 53:140-148

6. Kalenga M, Henquin JC 1987 Protein deprivation from the neonatal period impairs lung development in the rat. Pediatr Res 21:45-49

7. Kalenga M, Henquin JC 1987 Alteration of lung mechanics by protein-calorie malnutrition in weaned rats. Respir Physiol 68:29-39

8. Myers BA, Dubick MA, Gerreits J, Rucker RB, Jackson AC, Reiser KM, Williams SM, Last JA 1983 Protein deficiency: effects on lung mechanics and the accumulation of collagen and elastin in rat lung. J Nutr 113:2308and the
2315

9. Kivirikko KI, Laitinen O, Prockop DJ 1967 Modifications of a specific assay for hydroxyproline in urine. Anal Biochem 19:249-255

10. Lansing AI, Rosenthal TB, Alex M, Dempsey EW 1952 The structure and chemical characterization of elastic fibers as revealed by elastase and by electron microscopy. Anat Rec 114:555-575

11. Jackson DS, Cleary EG 1987 The determination of collagen and elastin. Methods Biochem Anal 15:25-76

12. Foster JA 1982 Elastin structure and biosynthesis: an overview. In: Cunningham LW, Frederiksen DW (eds) Methods in Enzymology, Vol 82A: Extracellular Matrix. Academic Press, New York, pp 559-587

13. Miller EJ, Gay S 1982 Collagen: an overview. In: Cunningham LW, Frederiksen DW (eds) Methods in Enzymology, Vol 82A: Extracellular Matrix. Academic Press, New York, pp 3-32

14. Partridge SM 1962 Elastin. Adv Prot Chem 17:227-302

15. Sahebjami H, MacGee J 1985 Effects of starvation on lung mechanics and biochemistry in young and old rats. $J$ Apply Physiol 58:778-784

16. Starcher BC 1977 Determination of the elastin content of tissues by measuring desmosine and isodesmosine. Anal Biochem 79:11-15

17. Setnikar I 1955 Origine e significato della proprieta meccaniche del polmone. Arch Fisiol 55:349-374

18. Mead J 1961 Mechanical properties of lungs. Physiol Rev 41:281-330

19. Johanson SG Jr, Pierce AK 1972 Effects of elastase, collagenase and papain on structure and function of rat lungs in vitro. J Clin Invest 51:288-293

20. Snider GL, Sherter CB, Koo KW, Karlinsky JB, Hayes JA, Franzblau C 1977 Respiratory mechanics in hamsters following treatment with endotracheal elastase or collagenase. J Appl Physiol 42:206-215

21. Kida K, Yashui S, Utsuyama M, Ofulue AF, Thurlbeck WM 1984 Lung changes resulting from intraperitoneal injections of porcine pancreatic elastase in suckling rats. Am Rev Respir Dir 130:1111-1117 